\title{
Liposomal honokiol, a potent anti-angiogenesis agent, in combination with radiotherapy produces a synergistic antitumor efficacy without increasing toxicity
}

\author{
Jia Hu, Li-juan Chen ${ }^{1}$, Li Liu, Xiang Chen, \\ Ping Chen, Guang-li Yang, Wen-li Hou, \\ Ming-hai Tang, Fan Zhang, Xian-huo Wang, \\ Xia Zhao and Yu-quan Wei \\ State Key Laboratory of Biotherapy \\ West China Hospital \\ West China Medical School, Sichuan University \\ Chengdu 610041, China \\ ${ }^{1}$ Corresponding author: Tel, 8628 85164063; \\ E-mail, lijuan17@ hotmail.com \\ DOI 10.3858/emm.2008.40.6.617
}

Accepted 15 July 2008

Abbreviations: H\&E, hematoxylin and eosin; Lipo-HNK, liposomal honokiol; Lipo-null, empty liposome; MVD, microvessel density; NS, normal saline; PEG, polyethylene glycol; RER, radiation enhancement ratio

\begin{abstract}
Honokiol is an active compound purified from magnolia that has been shown to induce cell differentiation, apoptosis, and anti-angiogenesis effects, as well as an enhancement in tumor growth delay in combination with chemotherapeutic agents in several mouse xenograft models. Our goal was to investigate the radiosensitization effect of honokiol on lung carcinoma. The radiosensitization effect of liposomal honokiol in Lewis lung carcinoma cells (LL/2) was analyzed using an in vitro clonogenic survival assay. For an in vivo study, Lewis lung carcinoma-bearing C57BL/6 mice were treated with either liposomal honokiol at $25 \mathrm{mg} / \mathrm{kg}$ or $5 \mathrm{~Gy}$ of single tumor radiation, or a combination of both over 12 days of treatment. The tumor growth delay and the survival time were evaluated. In addition, histological analysis of tumor sections was performed to examine changes by detecting the microvessel density and apoptosis in tumor tissues. In the clonogenic survival assay, LL/2 cells treated with $\mathrm{IC}_{50}$ Lipo-HNK for 24 $h$ showed a radiation enhancement ratio of 1.9. After 12 days of combination treatment, the tumor volume decreased $78 \%$ and produced an anti-tumor activity 1.3-fold greater than a predicted additive effect of hon-
\end{abstract}

okiol and radiation alone. This combination treatment also caused an 8.7 day delay in tumor growth. The cell cycle distribution and histological analysis demonstrated that liposomal honokiol has an anti-tumor effect via inducing apoptosis and inhibiting angiogenesis. Liposomal honokiol can enhance tumor cell radiosensitivity in vitro and in vivo, indicating that radiotherapy combined with liposomal honokiol can lead to greater anti-tumor efficacy.

Keywords: angiogenesis inhibitors; honokiol; liposomes; radiation tolerance; radiotherapy

\section{Introduction}

Lung cancer is a leading cause of death worldwide. Despite aggressive approaches in the treatment of lung cancer in the past few years, the five year survival rate is still less than $15 \%$ (Belinsky et al., 2006) and about $90 \%$ of deaths from lung cancer are thought to result from metastasis (Yano et al., 1997). Concurrent or sequential combinations of radiotherapy or chemotherapy with antiangiogenic therapy have been suggested as promising alternatives to single-agent therapies. Recent reports from experimental and clinical studies have proposed that such combinations have shown greater than additive effects due to apparent mutual reinforcement of these approaches (Bello et al., 1999; Abdollahi et al., 2003; Burdelya et al., 2006). Irradiation induces the production of VEGF or PDGF, which may promote tumor regrowth after irradiation (Gorski et al., 1999; Abdollahi et al., 2003; Colevas et al., 2003; Huber et al., 2005) and result in protection of vessels from radiation-induced cell damage. Thus, the rationale for this combination involves killing endothelial cells with radiotherapy and preventing their regrowth using an anti-angiogenesis inhibitor, which may act as a radiosensitizing compound to increase the deleterious effects of $X$-rays on tumor cells.

Honokiol is an active compound purified from magnolia that has drawn much attention for its anti-angiogenisis, cell differentiation, and apoptotic properties. Previous reports have demonstrated that honokiol can induce apoptosis in numerous cell lines, including murine endothelial SVR cells 
(Bai et al., 2003), human leukemia MOLT 4B cells (Hibasami et al., 1998), human colorectal carcinoma RKO cells (Wang et al., 2004), and human squamous lung cancer $\mathrm{CH} 27$ cells (Yang et al, 2002). The mechanism of anti-angiogenesis is down-regulation of the phosphorylation of vascular endothelial growth factor 2 (VEGFR2) (Bai et al., 2003). Differences in the action mechanisms and toxicity profiles of honokiol and radiotherapy indicate that the combination treatment has clinical potential.

We evaluated the ability of honokiol to enhance radiation-induced cytotoxity in the $L L / 2$ cell line. The anti-tumor effects of a combination consisting of liposomal honokiol and radiotherapy were systematically investigated both in vitro and in vivo. The combined mechanisms underlying the antitumor effects were investigated by observing the microvessel density and apoptosis in tumor tissues. Honokiol was encapsulated with liposome due to poor water solubility.

\section{Materials and Methods}

\section{Reagents}

High-purity soybean phosphatidyl choline, polyethylene glycol 4000 (PEG 4000), and cholesterol were purchased from Sigma Chemical Co, Inc. (St. Louis, MO). Honokiol was obtained from Chengdu Sikehua Biotechnology Co. Ltd. (Chengdu, China). Mouse monoclonal antibodies against human CD31 antibodies were purchased from BD Biosciences Co. (Dako LSAB kit, Dako). Biotinylated goat anti-rabbit IgG and biotinylated goat anti-rat IgG were obtained from Vector Laboratories. DAB coloring reagent, HRP labeled rabbit anti-mouse antibodies, and goat anti-rabbit were obtained from Beijing Zhongshanjinqiao Biotechnology Co. Ltd. (Beijing, China).

\section{Cell culture, tumor model, and irradiation}

The human lung cancer cell lines SPC-A1 and A549, and the Lewis mouse lung cancer cell line LL/2 were purchased from American Type Culture Collection, ATCC. SPC-A1, and A549 cells were incubated in RPMI-1640 medium (GIBICO) and LL/2 cells were incubated in DMEM medium (GIBICO). Cells were supplemented with $10 \%$ heat-inactivated FCS, 100 units $/ \mathrm{ml}$ of penicillin, and 100 units $/ \mathrm{ml}$ of streptomycin at $37^{\circ} \mathrm{C}$ with $95 \%$ relative humidity under $5 \% \quad \mathrm{CO}_{2}$. Cell concentrations were determined by counting trypsinized cells using a hemocytometer. For combination experiments, LL/2 cells were used for proli- feration and clonogenic survival assays based on pilot experiments.

The LL/2 bearing-tumor model was established in C57BL/6N mice (female; $18-20 \mathrm{~g}$ body weight; 8 weeks old). These mice were inoculated s.c. in the right posterior limb area with LL/2 cells $\left(5 \times 10^{5}\right)$. All mice were purchased from Sichuan University Animal Center (Chengdu, China). Photon irradiation was administered using a digital linear accelerator (Elekta Instrument AB, Sweden) at $6 \mathrm{MV}$ at a dose rate of $2.4 \mathrm{~Gy} / \mathrm{min}$. All animals used in the experiments were treated humanely in accordance with Institutional Animal Care and Use Committee guidelines.

\section{Preparation of liposomal honokiol}

Liposomal honokiol (Lipo-HNK) was prepared in our lab. Lecithin, cholesterol, PEG4000, and honokiol were mixed in weight ratios of $3: 3: 6: 4$ and dissolved in $15 \mathrm{ml}$ of chloroform/methanol at a ratio of $3: 2(\mathrm{v} / \mathrm{v})$. The mixture was gently warmed to $40^{\circ} \mathrm{C}$ in a round-bottomed flask, and the solvent was evaporated under a vacuum in a rotary evaporator until a thin lipid film was formed. The dried lipid films were left overnight and sonicated in $5 \%$ glucose solution, followed by concentration and lyophilization. The preparation of empty liposome (Lipo-null) was the same as Lipo-HNK without addition of honokiol. The final Lipo-HNK and Lipo-null were small multilamellar liposomes in a size range of $130 \pm 20 \mathrm{~nm}$ and $100 \pm 20 \mathrm{~nm}$, respectively. The unencapsulated drug was separated by passing the liposome preparation through a sterile Sephadex G-75 column (Pharmacia) eluted with PBS buffer at $\mathrm{pH}$ 7.4. The preparation was then filter sterilized by passage through a $0.22 \mu \mathrm{m}$ Millex filter. Lyophilized Lipo-HNK and Lipo-null were dissolved in NS for in vitro and in vivo studies.

\section{Cell growth inhibitory activities}

The cell growth-inhibitory activities of Lipo-HNK for SPC-A1, A549, and LL/2 cells were evaluated using an MTT assay (Zhang et al., 2005). SPC-A1, $A 549$, and $L L / 2$ cells were seeded in a 96-well plate at a plating density of $0.5-1 \times 10^{4} / \mathrm{ml}$, and cultured for $24 \mathrm{~h}$. Harvested cells were exposed to either Lipo-null or Lipo-HNK at various doses in fresh DMEM or RPMI-1640 medium at the indicated dosages. Free honokiol was dissolved in DMSO (the final concentration of DMSO did not exceed $0.1 \%$ ). Four replicates of one well each for each treatment dose were performed. The control groups were treated with Lipo-null that contained 
an equivalent dose of the polyethylene glycol liposomes of Lipo-HNK. Four to six wells were left as blanks. The plate was placed at $37^{\circ} \mathrm{C}$ in $5 \%$ $\mathrm{CO}_{2}$ for various times (12 h, $24 \mathrm{~h}, 36 \mathrm{~h}, 48 \mathrm{~h}$ ), and then cells were added to $20 \mu \mathrm{l}$ of MTT $(5 \mathrm{mg} / \mathrm{ml})$ for $3 \mathrm{~h}$ at $37^{\circ} \mathrm{C}$. After incubation, the supernatant was removed, the plate was reloaded with $0.15 \mathrm{ml}$ of DMSO, and the absorbance was measured at $570 \mathrm{~nm}$ using a Spectramax M5 Microtiter Plate Luminometer (Molecular Devices). The absorbance value of untreated cells was considered to be $100 \%$. $I C_{50}$ was defined by the concentration that caused a $50 \%$ absorbance decrease in drugtreated cells compared with untreated cells.

\section{Clonogenic survival assay}

After treatment with drugs and irradiation, cells were harvested and plated in triplicate in $6 \mathrm{~cm}$ dishes with densities varying from 200 to 10,000 cells/dish, depending on the radiation dose that the cells received (Xu et al., 2005). The cells were then cultured in a $37^{\circ} \mathrm{C}, 5 \% \mathrm{CO}_{2}$ incubator for 14 days. The culture dishes were stained with crystal violet. Colonies with more than 50 cells were scored as positive and the surviving fraction was determined. Radiation survival data were corrected using LipoHNK-treated only cells as a control. Cell survival curves were constructed using the one-hit multitarget equation. The radiation enhancement ratio (RER) was defined as RER = mean inactivation dose (radiotherapy)/mean inactivation dose (drug+ radiotherapy). A RER value of $>1$ was indicative of radiosensitization (Supiot et al, 2005).

\section{Flow cytometry and apoptosis analyses}

Evaluation of the cell cycle phase distribution was done using flow cytometry. LL/2 cells were seeded in a 6-well plate and treated with $18 \mu \mathrm{g} / \mathrm{ml}$ of Lipo-HNK, Lipo-null that contained an equivalent dose of the polyethylene glycol liposomes of Lipo$\mathrm{HNK}, 5 \mathrm{~Gy}$ of radiation, or $18 \mu \mathrm{g} / \mathrm{ml}$ of Lipo-HNK + $5 \mathrm{~Gy}$ of radiation. Cells were then collected, washed with PBS, and suspended in $1 \mathrm{ml}$ hypotonic fluorochrome solution that contained $50 \mu \mathrm{g}$ of propidium iodide/ml in $0.1 \%$ sodium citrate plus $0.1 \%$ Triton $\mathrm{X}-100$. The cells were analyzed using a flow cytometer (ESP Elite, Beckman-Coulter, Miami, FL). The numbers of apoptotic cells appearing in the cell cycle distribution were estimated using Listmode software.

\section{In vivo anti-tumor efficacy}

Tumor-bearing C57BL/6 mice were coded and divided randomly into 5 groups ( $n=10$ each group). Treatment was initiated at fifteen days when the tumor volume was approximately 500 $\mathrm{mm}^{3}$. The five groups of mice bearing tumors were treated with i.p. axenic NS (0.5 ml each), Lipo-HNK at $25 \mathrm{mg} / \mathrm{kg}$, Lipo-null at $37.5 \mathrm{mg} / \mathrm{kg}$, radiotherapy (RT, 5 Gy each), and Lipo-HNK combined with radiotherapy. The first three groups were given treatment every day for 10 days. The RT group was given treatment at a dose of 5 Gy every day for 5 days. In the combination treatment, mice were given a dose of 5 Gy/day for five days after treatment with Lipo-HNK for $40 \mathrm{~min}$, and then treated with Lipo-HNK for five days. Survival times and tumor volumes were observed. The tumor size was determined by measuring the largest and the perpendicular diameters every three days. Tumor volumes were calculated according to the formula $V=a \times b^{2} \times 0.52$, where $a$ is the largest superficial diameter and $b$ is the smallest superficial diameter. To detect necrosis, apoptosis, and the microvessel density, tumor tissues were excised, fixed in $10 \%$ formalin, and frozen at $-80^{\circ} \mathrm{C}$.

\section{Immunohistochemistry for microvessel, cell apoptosis, and proliferation analyses}

Tumor tissues were fixed in a $10 \%$ neutral buffered formalin solution and embedded in paraffin. Sections 3-5 $\mu \mathrm{m}$ thick were stained with hematoxylin and eosin (H\&E) for detection of necrosis. Induced apoptosis was evaluated by a TUNEL assay using an in situ cell death detection kit (Roche Molecular Biochemicals) following the manufacturer's protocol (Xiao et al., 2002). Cells undergoing apoptosis and necrosis were identified per one high-power microscope field. The anti-angiogenesis activity of Lipo-HNK was detected using frozen sections fixed in acetone and incubated with monoclonal rat anti-mouse CD31. After washing in PBS, sections were treated with secondary biotinylated goat anti-rat antibody. The sections were then stained with labeled streptavidin biotin reagents. The vessel density was determined by counting the number of microvessels per one high-power field (Blezinger et al., 1999; Lu et al., 2003).

\section{Statistical analysis}

Statistical comparisons were made with one-factor analysis of variance (ANOVA) and a two-tailed $t$ test. For the survival time of animals, Kaplan-Meier curves were established for each group, and survival was compared using a log rank test. Differences between means or ranks as appropriate were considered significant when yielding a $P<$ 
0.05. Results are presented as means \pm SD. Experiments were performed at least in triplicate.

\section{Results}

\section{Tumor cell proliferation due to Lipo-HNK treatment}

Before testing the effect of Lipo-HNK on the radiosensitivity of tumor cells, we first investigated the effects of free honokiol and Lipo-HNK alone on $\mathrm{LL} / 2$, A549, and SPC-A1 cell proliferation in a $24 \mathrm{~h}$ test with MTT. Lipo-HNK reduced the cell number with an $\mathrm{IC}_{50}$ of $17.7 \pm 0.8 \mu \mathrm{g} / \mathrm{ml}$ for $\mathrm{LL} / 2$, an $\mathrm{IC}_{50}$ of $19.9 \pm 1.2 \mu \mathrm{g} / \mathrm{ml}$ for $\mathrm{A} 549$, and an $\mathrm{IC}_{50}$ of $19.7 \pm$ $1.1 \mu \mathrm{g} / \mathrm{ml}$ for SPC-A1. The cell killing effects of Lipo-HNK and free HNK for all of the three cell
A

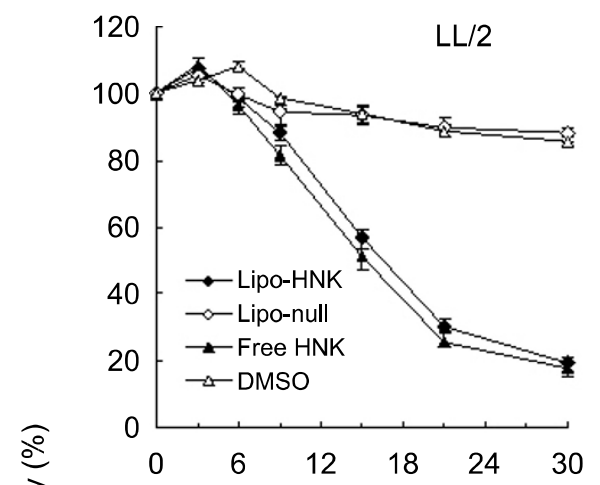

B

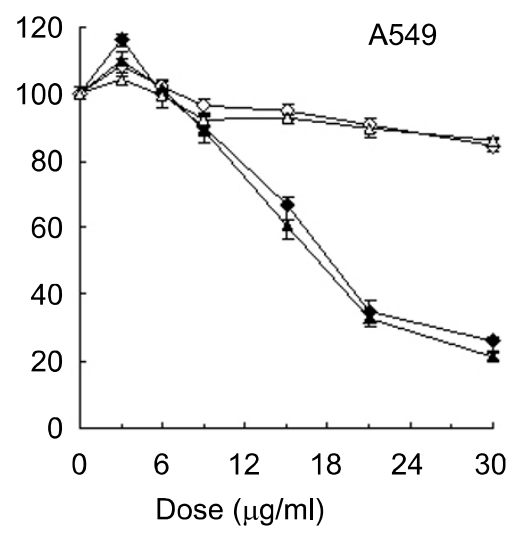

E

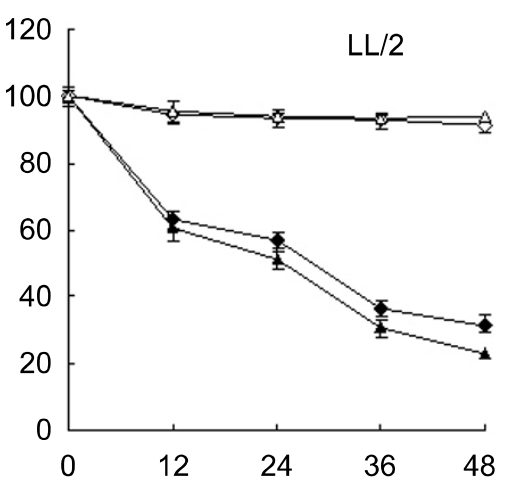

C

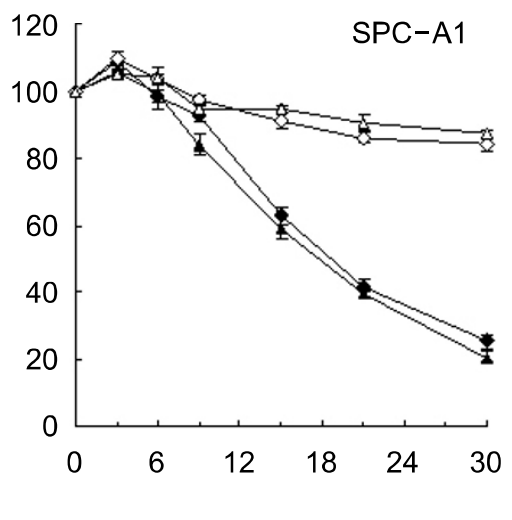

$\mathbf{F}$
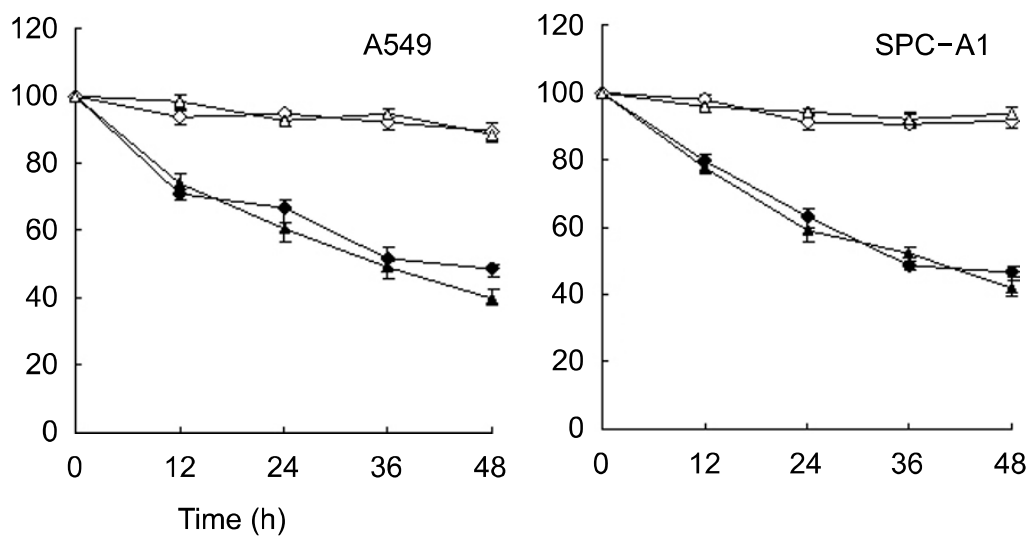

G<smiles>C=CCc1cc(-c2cccc(CC=C)c2O)ccc1O</smiles>

Honokiol

Figure 1. Dose and time-dependent inhibitions of proliferation of LL/2, A549, and SPC-A1 cells treated with Lipo-HNK $(\Delta)$, Lipo-null $(\diamond)$, free $H N K(\boldsymbol{\Delta})$, and DMSO $(\triangle)$. (A-C) LL/2, A549, and SPC-A1 cells were treated with various doses of Lipo-HNK and free honokiol for $24 \mathrm{~h}$. (D-F) LL/2, A549, and SPC-A1 cells were treated with $15 \mu \mathrm{g} / \mathrm{ml}$ of Lipo-HNK or free honokiol for various times. (G) Structure of honokiol. Data are expressed as mean \pm SD (n $=4$ per group at each time point). 
lines were dose and time-dependent (Figure 1). LL/2 cells were found to be more sensitive than other cells and were used for further experiments. Although free honokiol exhibited a slightly stronger effect in killing tumor cells than Lipo-HNK, there was no significant difference between them. In order to raise the water solubility and depress the toxicity towards normal organs, Lipo-HNK was used for in vivo experiments.

\section{Radiosensitization assessed by a clonogenic survival assay}

Clonogenic cell survival was assayed to determine

A

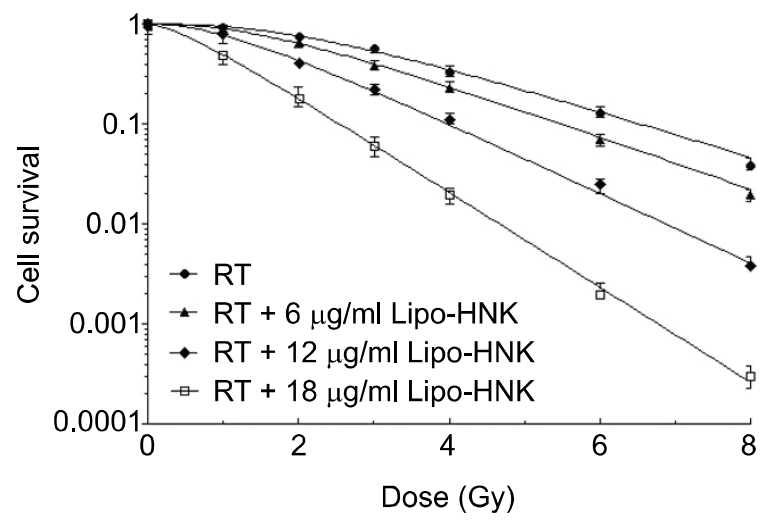

B

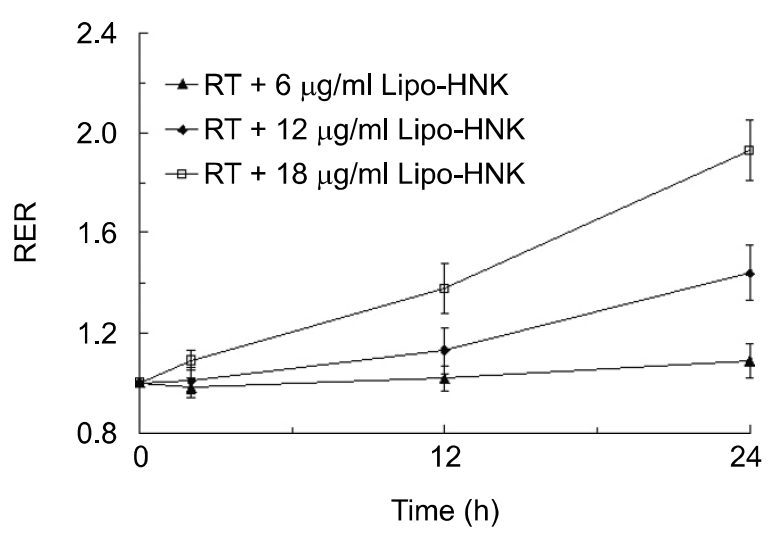

Figure 2. Effect of Lipo-HNK on the radiosensitivity of LL/2 cells. A, LL/2 cells were incubated with no drug $(\boldsymbol{O}), 6 \mu \mathrm{g} / \mathrm{ml}(\boldsymbol{\Lambda}), 12 \mu \mathrm{g} / \mathrm{ml}(\boldsymbol{\nabla})$, or $18 \mu \mathrm{g} / \mathrm{ml}(\square)$ of Lipo-HNK for $24 \mathrm{~h}$, followed by irradiation. Cell survival was assessed using a clonogenicity assay. Survival curves were corrected for the cytotoxicity induced by Lipo-HNK alone. B, LL/2 cells were exposed to $6 \mu \mathrm{g} / \mathrm{ml}(\boldsymbol{\Delta}), 12 \mu \mathrm{g} / \mathrm{ml}(\boldsymbol{\nabla})$, or $18 \mu \mathrm{g} / \mathrm{ml}(\square)$ of Lipo-HNK for $2 \mathrm{~h}, 12 \mathrm{~h}$, or $24 \mathrm{~h}$ prior to radiation. Cell survival was assessed using a clonogenicity assay. Values shown are the means \pm SD $(n=3$ per group at each time point). whether Lipo-HNK increases the sensitivity of tumor cells to radiation. According to the results with MTT, the doses of Lipo-HNK $6 \mu \mathrm{g} / \mathrm{ml}\left(\mathrm{IC}_{10}\right), 12 \mu \mathrm{g} / \mathrm{ml}$ $\left(\mathrm{IC}_{30}\right)$, and $18 \mu \mathrm{g} / \mathrm{ml}\left(\mathrm{IC}_{50}\right)$ were used to explore the sensitivity to radiation-induced cytotoxicity. LL/2 cells were irradiated after incubation with Lipo-HNK for $24 \mathrm{~h}$ and the survival at $6 \mu \mathrm{g} / \mathrm{ml}$ was not significantly different from untreated cell survival. The enhancement ratio (RER) was $1.09 \pm 0.07$ $(P>0.05)$. Both the $12 \mu \mathrm{g} / \mathrm{ml}$ and $18 \mu \mathrm{g} / \mathrm{ml}$ concentrations of Lipo-HNK produced a significant increase in radio sensitization with RER values of $1.44 \pm 0.11(P<0.05)$ and $1.93 \pm 0.12 \quad(P<$ $0.05)$, respectively (Figure $2 A)$. This combination resulted in synergistic effects compared to Lipo-HNK and irradiation alone.

We then examined the effect of the timing of irradiation during exposure to Lipo-HNK. LL/2 cells were incubated with Lipo-HNK at $6 \mu \mathrm{g} / \mathrm{ml}\left(\mathrm{IC}_{10}\right), 12$ $\mu \mathrm{g} / \mathrm{ml}\left(\mathrm{IC}_{30}\right)$, and $18 \mu \mathrm{g} / \mathrm{ml}\left(\mathrm{IC}_{50}\right)$ for a total of $24 \mathrm{~h}$. The cells were also irradiated either $2 \mathrm{~h}$ before drug addition or $2 \mathrm{~h}, 12 \mathrm{~h}$, or $24 \mathrm{~h}$ following LipoHNK addition. The greatest irradiation enhancement ratio was obtained when cells were incubated for $24 \mathrm{~h}$ prior to irradiation (Table 1). There was no difference between irradiation either $2 \mathrm{~h}$ before or after Lipo-HNK addition.

In order to assess whether the radiosensitivity enhancement effect of Lipo-HNK was time-depended, LL/2 cells were exposed to $6 \mu \mathrm{g} / \mathrm{ml}\left(\mathrm{IC}_{10}\right), 12$ $\mu \mathrm{g} / \mathrm{ml}\left(\mathrm{IC}_{30}\right)$, and $18 \mu \mathrm{g} / \mathrm{ml}\left(\mathrm{IC}_{50}\right)$ of Lipo-HNK for 2 $\mathrm{h}, 12 \mathrm{~h}$, or $24 \mathrm{~h}$, then the drugs were washed out prior to treatment with 1-8 Gy of radiation. The ability of Lipo-HNK to enhance the sensitivity of $\mathrm{LL} / 2$ cells increased with time (Figure 2B). When $\mathrm{LL} / 2$ cells were treated with $12 \mu \mathrm{g} / \mathrm{ml}$ of Lipo-HNK, the radiation enhancement ratio was $1.13 \pm 0.09$, for $12 \mathrm{~h}$ of incubation, and $1.44 \pm 0.11$ for $24 \mathrm{~h}$ of incubation. When LL/2 cells were treated with 18

Table 1. Effect of timing of irradiation on radiation enhancement ratio by Lipo-HNK.

\begin{tabular}{lccc}
\hline $\begin{array}{l}\text { Time of } \\
\text { radiation }\end{array}$ & $6 \mu \mathrm{g} / \mathrm{ml}$ & $12 \mu \mathrm{g} / \mathrm{ml}$ & $18 \mu \mathrm{g} / \mathrm{ml}$ \\
\hline $\begin{array}{l}2 \mathrm{~h} \text { before } \\
\text { Lipo-HNK }\end{array}$ & $1.03 \pm 0.04$ & $1.27 \pm 0.04$ & $1.45 \pm 0.06$ \\
$\begin{array}{l}2 \mathrm{~h} \text { after } \\
\text { Lipo-HNK }\end{array}$ & $0.94 \pm 0.05$ & $1.24 \pm 0.07$ & $1.47 \pm 0.08$ \\
$\begin{array}{l}12 \mathrm{~h} \text { after } \\
\text { Lipo-HNK }\end{array}$ & $1.05 \pm 0.04$ & $1.32 \pm 0.08$ & $1.63 \pm 0.11$ \\
$\begin{array}{c}24 \mathrm{~h} \text { after } \\
\text { Lipo-HNK }\end{array}$ & $1.09 \pm 0.07$ & $1.44 \pm 0.11$ & $1.93 \pm 0.12$ \\
\hline
\end{tabular}


$\mu \mathrm{g} / \mathrm{ml}$ of Lipo-HNK for $24 \mathrm{~h}$, the radiation enhancement ratio was $1.93 \pm 0.12$, which was almost 2 -fold greater than the $1.09 \pm 0.07$ value for $2 \mathrm{~h}$ of incubation. Our results demonstrated that LipoHNK increased the sensitivity to radiation-induced cytotoxicity in both a dose and time-dependent manner.

\section{Effect of Lipo-HNK and/or radiation on the cell cycle distribution}

To determine the effect of Lipo-HNK and IR on the cell cycle distribution, LL/2 cells were seeded in a 6 well plate. The Lipo-HNK treated group was incubated with $18 \mu \mathrm{g} / \mathrm{ml}\left(\mathrm{IC}_{50}\right)$ of Lipo-HNK for $24 \mathrm{~h}$ and/or 5 Gy of radiation. The cell cycle and apoptosis were analyzed by flow cytometry after 24 h. $L L / 2$ cells accumulated in the $G_{0} / G_{1}$-phase after treatment with Lipo-HNK alone $(>60 \%)$, with a corresponding decrease in the S-phase, compared with a control and with Lipo-null treatment results. The increase in the $G_{0} / G_{1}$ phase and the decrease in the $\mathrm{S}$-phase indicated that the cells were blocked in the $\mathrm{G}_{0} / \mathrm{G}_{1}$ phase. At $24 \mathrm{~h}$ after a $5 \mathrm{~Gy}$ dose of ionizing radiation, more than $20 \%$ of cells were in the $G_{2} / M$ phase and the percentage of cells in the S-phase was decreased to nearly half the value of the control. The Lipo-HNK and radiation combination in LL/2 cells produced a conspicuous S-phase decrease that was only 0.3 -fold of the

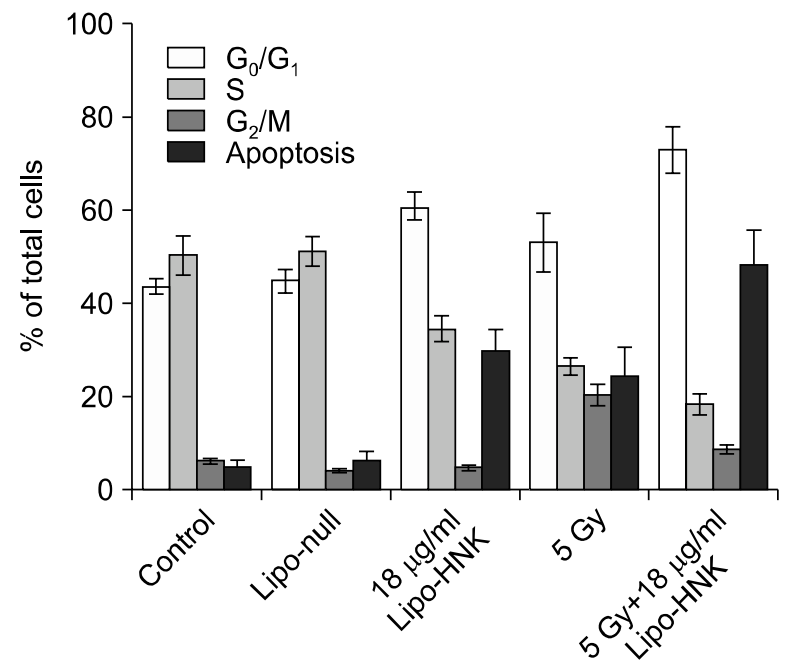

Figure 3. Effect of Lipo-HNK and/or radiation on the cell cycle distribution. LL/2 cells were exposed to $18 \mu \mathrm{g} / \mathrm{ml}$ of Lipo-HNK, Lipo-null that contained an equivalent dose of polyethylene glycol liposomes, 18 $\mu \mathrm{g} / \mathrm{ml}$ of Lipo-HNK, 5 Gy of radiation, and $5 \mathrm{~Gy}+18 \mu \mathrm{g} / \mathrm{ml}$ of Lipo-HNK, and then collected for analysis of the cell cycle phase distribution using flow cytometry. Data shown are representative of three independent experiments. Data are expressed as mean $\pm \mathrm{SD}$. control and 0.5 -fold of the Lipo-HNK and radiation treatment results alone. More than $70 \%$ of cells were in the $G_{0} / G_{1}$-phase (Figure 3).

Apoptosis was measured using the sub-G ${ }_{1}$ DNA content determined via flow cytometry. Cells in the sub- $G_{1}$ phase were considered to be apoptotic. The apoptosis rates in non-treated, Lipo-nulltreated, $18 \mu \mathrm{g} / \mathrm{ml}$ Lipo-HNK-treated, and $5 \mathrm{~Gy}$ radiation-treated cells were $4.8 \pm 1.3 \%, 6.1 \pm$ $2.2 \%, 29.7 \pm 4.6 \%$, and $24.4 \pm 6.2 \%$, respectively.

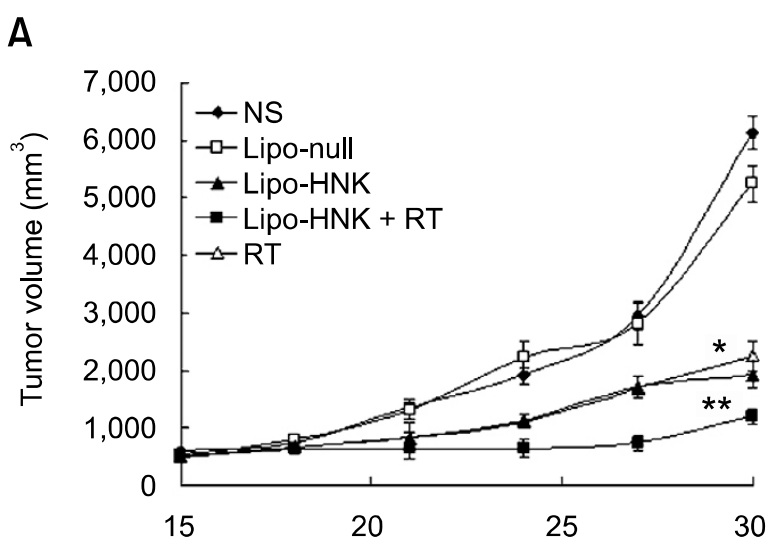

B

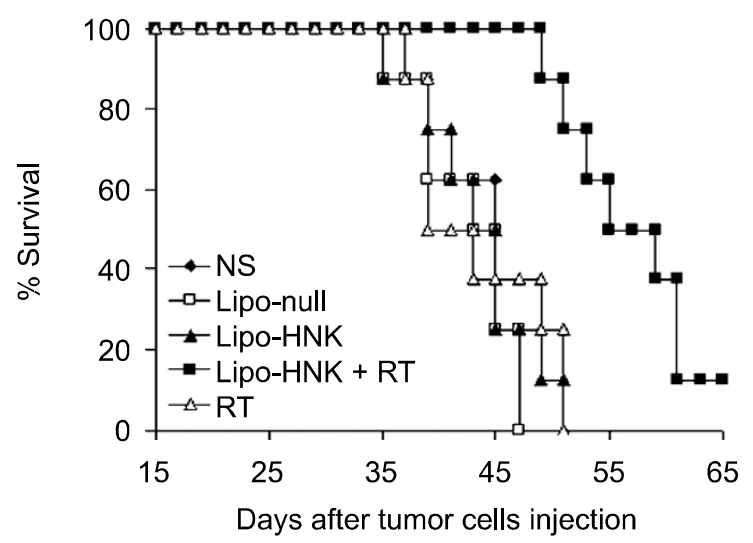

Figure 4. Effect of Lipo-HNK on tumor growth and survival of tumor-bearing mice. There were ten mice in each group. The five groups of tumor-bearing mice were treated with i.p. axenic NS $(\diamond)(0.5 \mathrm{ml}$ each), Lipo-HNK ( $(\boldsymbol{\Delta})$ at $25 \mathrm{mg} / \mathrm{kg}$, Lipo-null ( $\square$ ) at $37.5 \mathrm{mg} / \mathrm{kg}$ for 10 days, and RT $(\triangle)$ (5 Gy each) for 5 days. The combination group ( $)$ was treated with a dose of $5 \mathrm{~Gy} /$ day for five days after treatment with Lipo-HNK for 40 min, followed by continued treatment with Lipo-HNK for five days. Mice were inoculated s.c. in the right posterior limb with $L L / 2$ cells. (A) Inhibition of tumor growth in mice. Combination therapy resulting in significant tumor growth inhibition versus NS controls $(P<0.01)$; There was no difference between NS and the Lipo-null control $(P>0.05)$. (B) A significant increase in survival in the combination treated mice, compared with the NS control $(P<0.05$, by log-rank test), was found. Data are expressed as mean $\pm \mathrm{SD}$. ${ }^{*} P<0.05$ vs. control (NS). ${ }^{* *} P<$ 0.01 vs. control (NS). 
The apoptosis rate in the combination treatment was $48.2 \pm 7.4 \%$, which was nearly 2 -fold greater than for the Lipo-HNK or radiation treatments alone (Figure 3 ). This was confirmed by a TUNEL assay.

\section{Combination of honokiol and irradiation synergistically inhibits tumor growth}

Single Lipo-HNK significantly inhibited tumor growth in LL/2-bearing C57BL/6N mice compared with NS and Lipo-null control $(P>0.05)$ groups. However, the combination treatment group showed more significant tumor growth inhibition compared with both radiotherapy and liposomal honokiol treatments alone. After 12 days of combination treatment, the tumor volume was $734.4 \pm 256.1 \mathrm{~mm}^{3}$, which was decreased $78 \%$ compared with the untreated tumor volume. The single Lipo-HNK and radio- therapy treatments only reduced the tumor sizes by $42 \% \quad\left(1,707.6 \pm 523.1 \mathrm{~mm}^{3}\right.$ and $1694.1 \pm$ $291.1 \mathrm{~mm}^{3}$, respectively) compared with the untreated tumor volume $\left(2,947.3 \pm 1,330.0 \mathrm{~mm}^{3}\right)$ (Figure 4A). On day 12 after the combination treatment, the synergistic ratio reached a value of 1.34 , showing that Lipo-HNK synergistically (ratio $>1$ ) enhances the antitumor efficacy of radiation (Table 2). However, on day 15 after the combination treatment, the ratio was decreased to 1.02 , showing only an additive effect. The combination treatment resulted in a significant improvement in the survival time (Figure 4B). The Lipo-HNK/ radiotherapy combination treatment resulted in an 8.7 day delay in tumor growth to reach a volume of $1,000 \mathrm{~mm}^{3}$. In contrast, Lipo-HNK and radiotherapy treatments alone resulted in 2.7 and 3.2 day delays in tumor growth to reach the same volume. The delay time

Table 2. Effect of combining Lipo-HNK and ionizing radiation measured by fractional tumor volume relative to untreated controls ${ }^{a}$.

\begin{tabular}{cccccc}
\hline $\begin{array}{c}\text { Day of } \\
\text { treatment }\end{array}$ & Lipo-HNK & Irradiation & $\begin{array}{c}\text { Combined } \\
\text { Expected) }^{\mathrm{b}}\end{array}$ & $\begin{array}{c}\text { Combined } \\
\text { (Observed) }^{2}\end{array}$ & $\begin{array}{c}\text { Expected/ } \\
\text { Observed }^{\mathrm{C}}\end{array}$ \\
\hline 6 & 0.6035 & 0.617 & 0.3724 & 0.4695 & 0.7932 \\
9 & 0.5902 & 0.5814 & 0.3431 & 0.3307 & 1.0375 \\
12 & 0.5794 & 0.5748 & 0.333 & 0.2492 & 1.3363 \\
15 & 0.4104 & 0.4387 & 0.2017 & 0.1987 & 1.016 \\
\hline
\end{tabular}

${ }^{a}$ mean tumor volume experimental/mean tumor volume control; ${ }^{b}$ mean fractional tumor volume of Lipo-HNK $\times$ mean fractional tumor volume of radiation; 'Obtained by dividing the expected fractional tumor volume by the observed fractional tumor volume. A ratio of $>1$ indicates a synergistic effect, and a ratio of $<1$ indicates a less than additive effect.
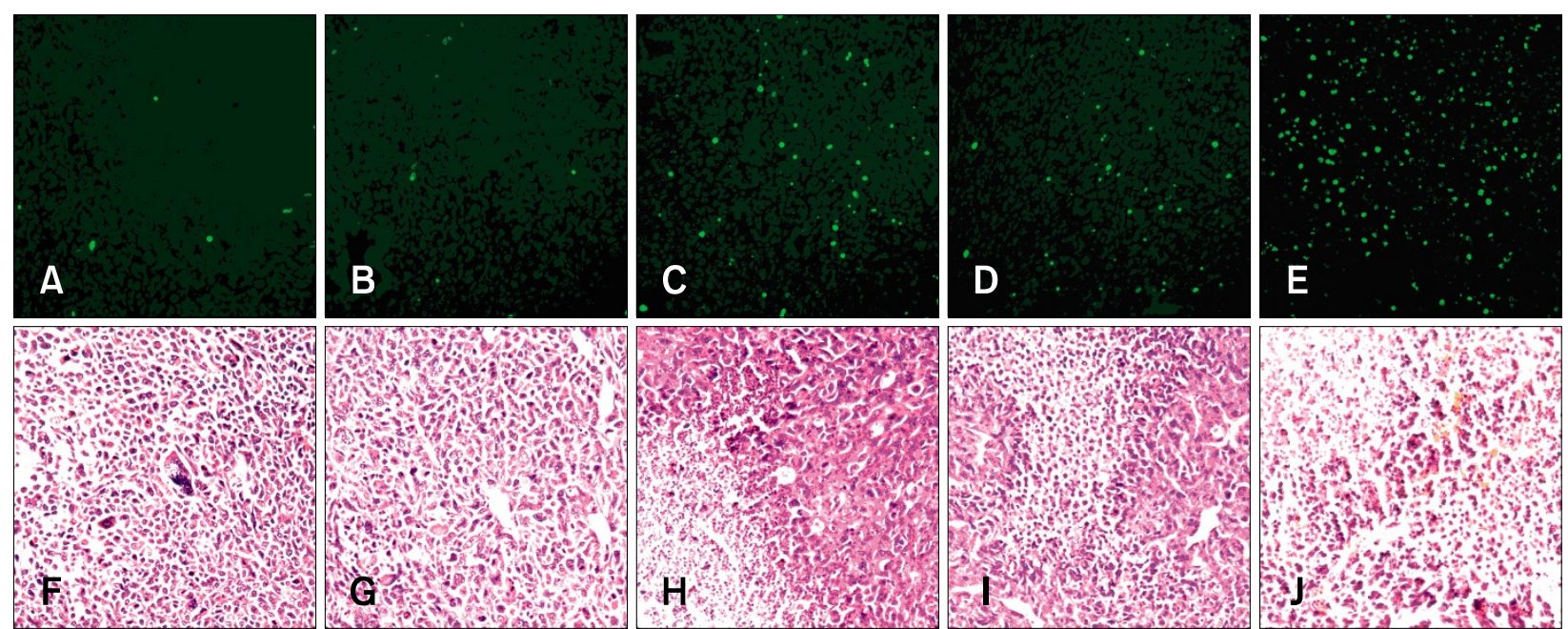

Figure 5. Necrosis and induction of apoptosis assayed by immunohistochemistry with H\&E and TUNEL staining, respectively. Representative histological features of LL/2 tumors at $200 \times$ magnification were documented. (A-E) TUNEL assay for apoptotic cells. Lipo-HNK (C) and RT (D) treatment groups exhibited an effective induction of apoptosis in tumor tissues compared with NS (A) and Lipo-null (B) groups $(P<0.05)$. More TUNEL-positive cells were observed in the combination group (E) than in the single treatment Lipo-null and RT groups $(P<0.05)$. (F-J) H\&E for necrosis and blood vessels. Single Lipo-HNK $(H)$, radiotherapy (I) treatment sections revealed a great quantity of necrosis, but less than for the combination of Lipo-HNK and radiotherapy (J). NS (F) and Lipo-null (G) control groups exhibited little necrosis and some of the tumor cells exhibited active proliferation. 
of tumor growth was defined as the average difference in time for the tumor volume to reach $1,000 \mathrm{~mm}^{3}$ between the treated group and the NS control group. The average time was 6.5 days for the NS control group.

\section{Synergistic induction of apoptosis}

DNA fragmentation determined by TUNEL detection revealed differences between groups. Although treatment with either Lipo-HNK or irradiation increased apoptosis compared to the untreated groups, the combination treatment induced more significant apoptosis. Significant increases in the number of TUNEL-positive nuclei were found for the combined treatment compared with the Lipo$\mathrm{HNK}$ and irradiation treatments alone (Figure 5A-E).

H\&E staining was performed to measure necrosis and the number of blood vessels in paraffin sections. Tissue sections of Lipo-HNK and radiotherapy treatment specimens exhibited significant necrosis, but less than for the combination of Lipo-HNK and radiotherapy treatments. NS and Lipo-null control group specimens exhibited little necrosis and some of the tumor cells showed active proliferation

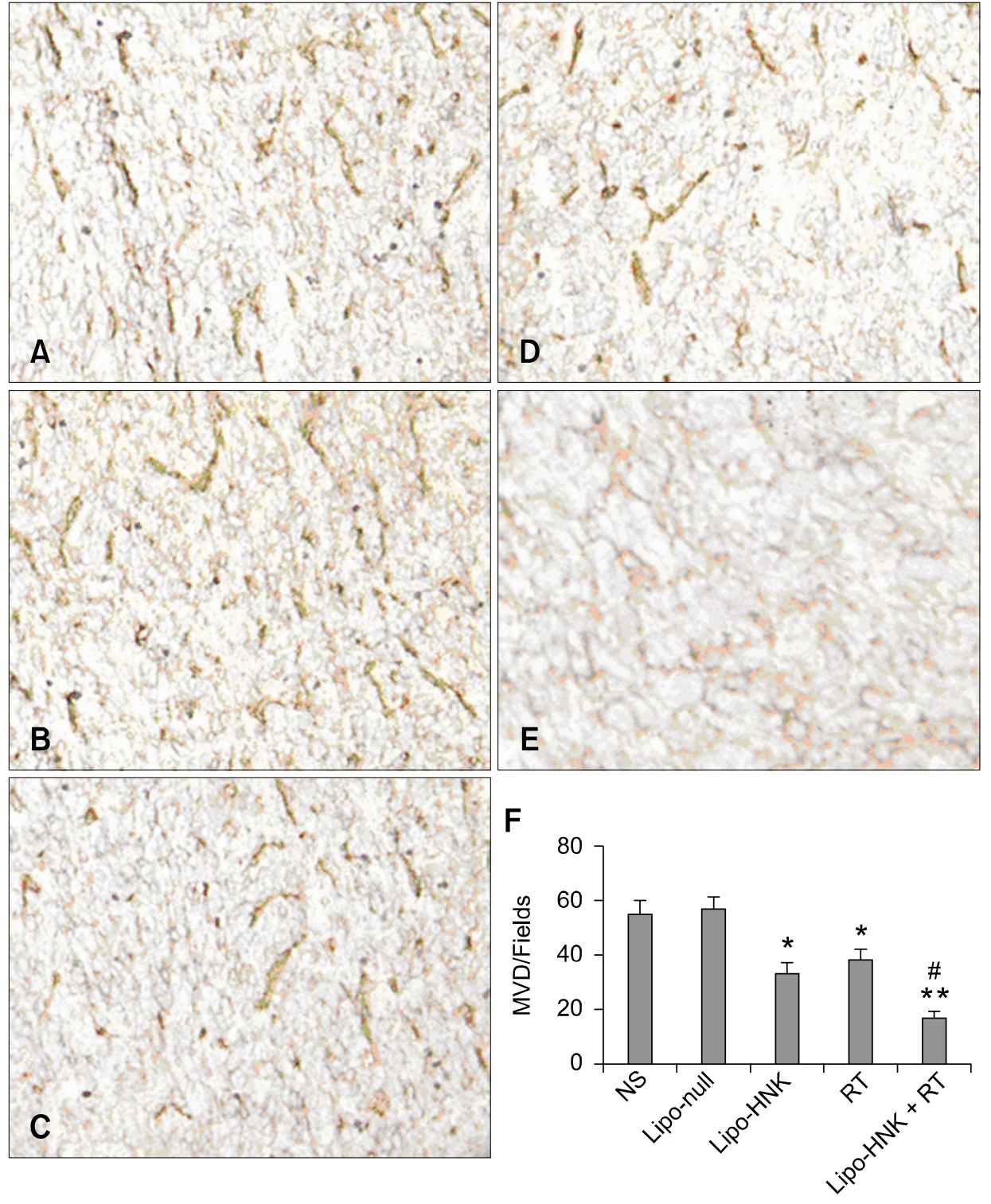

Figure 6. Tumor angiogenesis was assessed using immunohistochemical staining with anti-CD31 antibody on frozen tumor tissue sections. Microvessel counting was performed at $200 \times$. Significantly reduced numbers of blood vessels in tumors treated with the combination $(\mathrm{E})$ in comparison with Lipo-HNK alone (C) or radiation alone (D). There was no difference between NS (A) and Lipo-null (B) in MVD $(P<$ $0.05)$. Data represent the mean \pm SD of microvessels per high-power field. ${ }^{*} P<0.05$ vs. control (NS). ${ }^{* *}$ $P<0.01$ vs. control (NS). " combination index $>1$. 
(Figure 5F-J).

\section{Synergistic inhibition of angiogenesis}

Angiogenesis within tumor tissues was estimated in tumor sections stained with an antibody reactive to CD31 and quantified as described in Materials and Methods. Compared to untreated groups, both liposomal honokiol and irradiation treatments resulted in apparent inhibition of angiogenesis in tumors. The average numbers of blood vessels observed at a magnification of $200 \times$ in tumors treated with NS, Lipo-null, Lipo-HNK, irradiation, and the combination of Lipo-HNK and irradiation were $55.8 \pm 5.7, \quad 57.2 \pm 4.3, \quad 33.7 \pm 4.1, \quad 38.6 \pm 4.5$, and $16.2 \pm 3.4$, respectively. The combination of Lipo-HNK and irradiation resulted in enhanced inhibition of angiogenesis and revealed a synergistic effect in the tumor MVD (Figure 6A-F) (the synergistic index was 1.44). Significantly reduced numbers of blood vessels in tumors treated with a combination in comparison with Lipo-HNK and radiation alone $(P<0.01)$ indicated that a reduction in tumor vascularity contributes to enhanced tumor regression.

\section{Toxicity assays}

All groups of mice tolerated Lipo-HNK and no gross signs of cumulative adverse consequences were observed, such as huddling, weight loss, ruffling of fur, reduced life span, unusual behavior, and unusual feeding habits. Furthermore, no pathologic changes in the liver, lung, kidney, spleen, brain, heart, pancreas, intestines, or bone marrow were found under microscopic examination. In order to measure the systemic toxicity of the treatments, pathologic inspection was assessed by hematoxylin \& eosin staining of sections. No pathologic changes in the liver, lung, kidney, spleen, brain, heart, pancreas, intestines, or bone marrow were found under microscopic examination (data not shown).

\section{Discussion}

Anti-angiogenesis therapy has become a novel method for the treatment and prevention of tumors by restraining or destroying tumor vessels (Marshall et al., 1998; Mauceri, 1998; Marx, 2000, 2003; Rakhmilevich et al., 2004; Garkavtsev et al., 2004). However, this therapy can not lead to complete regression of the tumor. Continued medication is usually required to prevent dormant tumor growth. Previous research has indicated that the content of VEGF in the blood of tumor patients is significantly heightened during radiotherapy treatment, and there is a correlation between the expression level of VEGF and the prognosis after radiotherapy. Radiation can induce the creation of VEGF by the MAPK pathway, so that tumor vessels form and degrade the therapeutic effect of the radiotherapy. Hence, angiogenesis inhibitors have shown a fairly strong synergistic effect when combined with radiotherapy (Huber et al., 2005).

Honokiol has been reported to have anti-angiogenesis effects (Yang et al., 2002) and can induce apoptosis in many tumor cells (Hibasami et al., 1998; Chen et al., 2004; Wang et al., 2004; Ishitsuka et al., 2005). The mechanism of its anti-angiogenesis effect is interference with the phosphorylation of vascular endothelial growth factor 2 (VEGFR2) (Bai et al., 2003). A recent study has confirmed that honokiol can inhibit vasiformation in the microenvironment of the bone marrow and kill tolerated multiple myeloma cells (Ishitsuka et al., 2005).

This study demonstrated for the first time that liposomal honokiol enhances the radiation response of LL/2 cells in in vitro and in in vivo in tumor xenograft models. In a clonogenicity assay, LipoHNK exhibited an enhancement to radiosensitization in LL/2 cells in both a dose and timedependent manner. Cell cycle studies showed that honokiol combined with radiotherapy can induce $\mathrm{LL} / 2$ cells to arrest in the $\mathrm{G}_{0} / \mathrm{G}_{1}$ phase with a corresponding decrease in the S-phase, indicating that radiation combined with honokiol interrupts tumor cell division. CD31 staining of blood vessel endothelial cells to visualize the microvessel density in the combination treatment group showed significant inhibition of tumor vessel formation. Honokiol combined with radiotherapy apparently reduced the vessel number compared with NS and LipoHNK treatments alone. H\&E and TUNEL staining indicated that honokiol has the effect of inducing apoptosis in LL/2 tumor cells, and can enhance the effect of inducing apoptosis when combined with radiotherapy.

We investigated the dose-effect relationship of Lipo-HNK in vivo (Liu et al.) using four doses of honokiol from $5 \mathrm{mg} / \mathrm{kg}$ to $50 \mathrm{mg} / \mathrm{kg}$ and found that $25 \mathrm{mg} / \mathrm{kg}$ presented a favorable therapeutic efficacy. In order to mimic the frequently used clinical method, we applied a routine divided method for radiotherapy. The $\mathrm{RT}$ group was administered a dose of 5 Gy every day for 5 days and the combination group was administered a dose of 5 Gy/day for five days after treatment with Lipo-HNK for $40 \mathrm{~min}$, followed by continued treatment with Lipo-HNK for five days. This combination treatment significantly improved the survival time versus 
other groups and resulted in a delay in tumor growth compared with liposomal honokiol and radiotherapy treatments alone. A synergistic relationship in tumor volume, angiogenesis, apoptosis, and proliferation was demonstrated according to a combined index calculation. Our findings indicate that angiogenesis inhibitors have a fairly strong synergistic effect on a combination therapy with radiotherapy. It should be pointed out that the total irradiation dose and the total dosage time for the mice in our study were deficient compared with clinical therapies. Better therapeutic efficacy may be obtained if the irradiation dose is increased and the time is lengthened.

Previous in vitro and in vivo studies have shown that encapsulating antitumor agents with liposome is an effective way to avoid rapid clearance and short circulation time in order to significantly prolong the plasma residence time of drugs (Boman et al., 1995; Emerson et al., 2000; Tardi et al., 2000; Lee et al., 2002). As previously reported (Yi Liu et al., Fan et al., 1995), defects in the capillary endothelium of tumor vasculature are typically in the size range of 400-600 $\mathrm{nm}$. Liposomes, having a diameter smaller than $400 \mathrm{~nm}$, can efficiently accumulate within the tumor interstitial space. In a previous study, we developed honokiol encapsulated with liposomes to overcome problems of water insolubility and toxicity towards normal organisms (Liu et al., 2008). We found the toxicity of free honokiol towards mice is strong and water insolubility hampers honokiol application for intravenous injection. MTT results indicated that tumor cytotoxicity is not significantly different between free honokiol and Lipo-HNK. Encapsulating honokiol with liposome does not degrade the effect on tumor cells. Our experiments demonstrated that there are no significant differences for both tumor growth and mouse life span between Lipo-null and NS control groups, and no visible side effects of Lipo-null were observed. Thus, the use of a liposomal formulation is feasible.

The data presented in this report indicate that liposomal honokiol combined with RT mediates a potent inhibition of Lewis lung cancer tumor growth and prolongs the survival time of tumor-bearing mice. In addition, a combination treatment results in significantly increased necrosis and a synergistic decrease in tumoral blood vessels and angiogenesis. Honokiol encapsulated with liposome presents the favorable effect of radiosensitization and organism tolerance. Our findings support the design of treatment strategies that combine IR with liposomal honokiol, a potent anti-angiogenesis inhibitor. Further exploration of the potential application of this combined approach in the treatment of lung cancer is indicated.

\section{Acknowledgements}

This work was supported by the National Basic Research Program of China (2004CB518800 and 2004CB518706), the National 863 Program, the National Natural Science Foundation of China, and the New Century Talent Foundation of the Ministry of Education of China (2005).

\section{References}

Abdollahi A, Lipson KE, Han X, Krempien R, Trinh T, Weber KJ, Hahnfeldt P, Hlatky L, Debus J, Howlett AR, Huber PE. SU5416 and SU6668 attenuate the angiogenic effects of radiationinduced tumor cell growth factor production and amplify the direct anti-endothelial action of radiation in vitro. Cancer Res 2003;63:3755-63

Abdollahi A, Lipson KE, Sckell A, Zieher $H$, Klenke $F$, Poerschke D, Roth A, Han X, Krix M, Bischof M, Hahnfeldt P, Grone HJ, Debus J, Hlatky L, Huber PE. Combined therapy with direct and indirect angiogenesis inhibition results in enhanced antiangiogenic and antitumor effects. Cancer Res 2003;63:8890-8

Bai X, Cerimele F, Ushio-Fukai M, Waqas M, Campbell PM, Govindarajan B, Der CJ, Battle T, Frank DA, Ye K, Murad E, Dubiel W, Soff G, Arbiser JL. Honokiol, a small molecular weight natural product, inhibits angiogenesis in vitro and tumor growth in vivo. J Biol Chem 2003;278:35501-7

Belinsky SA, Liechty KC, Gentry FD, Wolf HJ, Rogers J, Vu K, Haney J, Kennedy TC, Hirsch FR, Miller Y, Franklin WA, Herman JG, Baylin SB, Bunn PA, Byers T. Promoter hypermethylation of multiple genes in sputum precedes lung cancer incidence in a high-risk cohort. Cancer Res 2006;66: 3338-44

Bello L, Carrabba G, Giussani C, Lucini V, Cerutti F, Scaglione F, Landré J, Pluderi M, Tomei G, Villani R, Carroll RS, Black PM, Bikfalvi A. Low-dose chemotherapy combined with an antiangiogenic drug reduces human glioma growth in vivo. Cancer Res 1999;61:7501-6

Blezinger P, Wang J, Gondo M, Quezada A, Mehrens D, French M, Singhal A, Sullivan S, Rolland A, Ralston R, Min W. Systemic inhibition of tumor growth and tumor metastases by intramuscular administration of the endostatin gene. Nat Biotechnol 1999;17:343-8

Boman NL, Bally MB, Cullis PR, Mayer LD, Webb MS. Encapsulation of vincristine in liposomes reduces toxicity and improves antitumor efficacy. J Liposome Res 1995;5: 523-41

Burdelya LG, Komarova EA, Hill JE, Browder T, Tararova ND, Mavrakis L, DiCorleto PE, Folkman J, Gudkov AV. Inhibition of p53 response in tumor stroma improves efficacy of anticancer treatment by increasing antiangiogenic effects of chemotherapy and radiotherapy in mice. Cancer Res 2006; 66:9356-61

Chen F, Wang T, Wu YF, Gu Y, Xu XL, Zheng S, Hu X. 
Honokiol: a potent chemotherapy candidate for human colorectal carcinoma. World J Gastroenterol 2004;10: 3459-63

Colevas AD, Brown JM, Hahn S, Mitchell J, Camphausen K, Coleman $\mathrm{CN}$. Development of investigational radiation modifiers. J Natl Cancer Inst 2003;95:646-51

Emerson DL, Bendele R, Brown E, Chiang S, Desjardins JP, Dihel LC, Gill SC, Hamilton M, LeRay JD, Moon-McDermott L, Moynihan K, Richardson FC, Tomkinson B, Luzzio MJ, Baccanari D. Antitumor efficacy, pharmacokinetics, and biodistribution of NX 211: a low-clearance liposomal formulation of lurtotecan. Clin Cancer Res 2000;6:1903-12

Garkavtsev I, Kozin SV, Chernova O, Xu L, Winkler F, Brown $\mathrm{E}$, Barnett GH, Jain RK. The candidate tumor suppressor protein ING4 regulates brain tumor growth and angiogenesis. Nature 2004;428:328-32

Geng L, Donnelly E, McMahon G, Lin PC, Sierra-Rivera E, Oshinka H, Hallahan DE. Inhibition of vascular endothelial growth factor receptor signaling leads to reversal of tumor resistance to radiotherapy. Cancer Res 2001;61:2413-9

Gorski DH, Beckett MA, Jaskowiak NT, Calvin DP, Mauceri HJ, Salloum RM, Seetharam S, Koons A, Hari DM, Kufe DW, Weichselbaum RR. Blockage of the vascular endothelial growth factor stress response increases the antitumor effects of ionizing radiation. Cancer Res 1999;59:3374-8

Hibasami H, Achiwa Y, Katsuzaki H, Imai K, Yoshioka K, Nakanishi K, Ishii Y, Hasegawa M, Komiya T. Honokiol induces apoptosis in human lymphoid leukemia Molt 4B cells. Int J Mol Med 1998;2:671-3

Huber PE, Bischof M, Jenne J, Heiland S, Peschke P, Saffrich R, Gröne HJ, Debus J, Lipson KE, Abdollahi A. Trimodal cancer treatment: beneficial effects of combined antiangiogenesis, radiation, and chemotherapy. Cancer Res 2005; 65:3643-55

Ishitsuka K, Hideshima T, Hamasaki M, Raje N, Kumar S, Hideshima H, Shiraishi N, Yasui H, Roccaro AM, Richardson P, Podar K, Le Gouill S, Chauhan D, Tamura K, Arbiser J, Anderson KC. Honokiol overcomes conventional drug resistance in human multiple myeloma by induction of caspase-dependent and independent apoptosis. Blood 2005;106:1794-800

Lee CG, Heijn M, di Tomaso E, Griffon-Etienne G, Ancukiewicz M, Koike C, Park KR, Ferrara N, Jain RK, Suit HD, Boucher Y. Anti-vascular endothelial growth factor treatment augments tumor radiation response under normoxic or hypoxic conditions. Cancer Res 2000;60:5565-70

Lee CM, Tanaka T, Murai T, Kondo M, Kimura J, Su W, Kitagawa T, Ito T, Matsuda H, Miyasaka M. Novel condroitin sulfate-binding cationic liposomes loaded with cisplatin efficiently suppress the local growth and liver metastasis of tumor cells in vivo. Cancer Res 2002;62:4282-8

Liu Y, Chen L, Fan L, Yang G, Zhao X, Wei Y. Enhancement of therapeutic effectiveness by combining pegylated liposomal of honokiol and cisplatin in ovarian carcinoma. Int J Gynecol Cancer 2008;18:652-9
Lu Y, Wei YQ, Tian L, Zhao X, Yang L, Hu B, Kan B, Wen YJ, Liu F, Deng HX, Li J, Mao YQ, Lei S, Huang MJ, Peng F, Jiang Y, Zhou H, Zhou LQ, Luo F. Immunogene therapy of tumors with vaccine based on xenogeneic epidermal growth factor receptor. Journal of Immunology 2003;170:3162-70

Marshall E. The road blocks to angiogenesis blockers. Science 1998;280:997-9

Marx J. Tumor angiogenesis: gene expression patterns identified. Science 2000;289:1121-2

Marx J. Angiogenesis: a boost for tumor starvation. Science 2003;301:452-4

Mauceri HJ, Hanna NN, Beckett MA, Gorski DH, Staba MJ, Stellato KA, Bigelow K, Heimann R, Gately S, Dhanabal M, Soff GA, Sukhatme VP, Kufe DW, Weichselbaum RR. Combined effects of angiostatin and ionizing radiation in antitumour therapy. Nature 1998;394:287-91

Rakhmilevich AL, Hooper AT, Hicklin DJ, Sondel PM. Treatment of experimental breast cancer using interleukin-12 gene therapy combined with anti-vascular endothelial growth factor receptor-2 antibody. Molecular Cancer Therapeutics 2004;3:969-76

Sonveaux P, Brouet A, Havaux X, Grégoire V, Dessy C, Balligand $\mathrm{JL}$, Feron $\mathrm{O}$. Irradiation-induced angiogenesis through the up-regulation of the nitric oxide pathway: Implications for tumor radiotherapy. Cancer Res 2003; 63:1012-9

Supiot S, Gouard S, Charrier J, Apostolidis C, Chatal JF, Barbet J, Davodeau F, Cherel M. Mechanisms of cell sensitization to a radioimmunotherapy by doxorubicin or paclitaxel in multiple myeloma cell lines. Clin Cancer Res 2005;11:7047-52

Tardi P, Choice E, Masin D, Redelmeier T, Bally M, Madden TD. Liposomal encapsulation of topotecan enhances anticancer efficacy in murine and human xenograft models. Cancer Res 2000;60:3389-93

Wang T, Chen F, Chen Z, Wu YF, Xu XL, Zheng S, Hu X. Honokiol induces apoptosis through p53-independent pathway in human colorectal cell line RKO. World J Gastroenterol 2004;10:2205-8

Xiao F, Wei Y, Yang L, Zhao X, Tian L, Ding Z, Yuan S, Lou Y, Liu F, Wen Y, Li J, Deng H, Kang B, Mao Y, Lei S, He Q, Su J, Lu Y, Niu T, Hou J, Huang MJ. Gene therapy for cancer based on the angiogenesis inhibitor, vasostatin. Gene Therapy 2002;9:1207-13

Xu L, Yang D, Wang S, Tang W, Liu M, Davis M, Chen J, Rae JM, Lawrence T, Lippman ME. (-)-Gossypol enhances response to radiation therapy and results in tumor regression of human prostate cancer. Mol Cancer Ther 2005;4:197-205

Yang SE, Hsieh MT, Tsai TH, Hsu SL. Downmodulation of $\mathrm{Bcl}-\mathrm{XL}$, release of cytochrome $\mathrm{c}$ and sequential activation of caspases during honokiol-induced apoptosis in human squamous lung cancer $\mathrm{CH} 27$ cells. Biochem Pharmacol 2002;63:1641-51 
Yano S, Nishioka Y, Nokihara H, Sone S. Macrophage colony-stimulating factor gene transduction into human lung cancer cells differentially regulates metastasis formations in various organ microenvironments of natural killer celldepleted. Cancer Res 1997;57:784-90

Yuan F, Dellian M, Fukumura D, Leunig M, Berk DA, Torchilin VP, Jain RK. Vascular permeability in a human tumor xenograft: molecular size dependence and cutoff size. Cancer Res 1995;55:3752-6

Zhang SY, Park KW, Oh S, Cho HJ, Cho HJ, Park JS, Cho YS, Koo BK, Chae IH, Choi DJ, Kim HS, Lee MM. NF-kB decoy potentiates the effects of radiation on vascular smooth muscle cells by enhancing apoptosis. Exp Mol Med 2005; $37: 18-26$ 